\title{
FAKTOR YANG MEMPENGARUHI PENGETAHUAN REMAJA DALAM PENCEGAHAN HIV AIDS DI SMA N 7 KOTA PEKANBARU
}

\author{
Dona Martilova \\ PSD III Kebidanan, STIKes Payung Negeri Pekanbaru \\ Jl. Tamtama No 6 Labuh Baru. Pekanbaru-Riau-Indonesia \\ Email : dhonalova@gmail.com
}

Kata Kunci :

Remaja, HIV/AIDS

Keywords:

Teenagers, HIV / AIDS

\section{Info Artikel}

Tanggal dikirim: 27-12-2019

Tanggal direvisi: $7-1-2020$

Tanggal diterima: $23-1-2020$

DOI : 10.36341 jomis.v4i1.1072

Attribution-NonCommercial 4.0

International. Some rights

reserved

\begin{abstract}
ABSTRAK :
HIV adalah kelompok Retrovirus yang menyerang sistem kekebalan tubuh manusia, sedangkan kumpulan kondisi klinis tertentu yang merupakan hasil akhir dari infeksi HIV disebut AIDS (Acquired Immune Deficiency Syndrome). Kurang lebih 50\% dari pengidap AIDS di Indonesia adalah kelompok umur remaja. Pada masa remaja sering kali timbul rasa ingin mencoba-coba ini merupakan hal penting bagi kesehatan reproduksi remaja. Perilaku ingin mencoba hal yang baru jika didorong oleh rangsangan seksual dapat membawa remaja masuk pada hubungan seks pranikah dengan salah satu akibatnya penularan penyakit kelamin termasuk HIV/AIDS. Tujuan penelitian ini adalah untuk mengetahui faktor yang mempengaruhi pengetahuan remaja dalam pencegahan HIV dan AIDS di SMA N 7 Kota Pekanbaru. Penelitian ini merupakan penelitian analitik dengan pendekatan Cross Sectional dimana variabel independenya adalah Umur, Sikap, Sumber Informasi sedangkan variabel dependennya adalah Pengetahuan Remaja. Teknik pengambilan sampel dengan stratifikasi dengan jumlah responden 83 siswa. Hasil penelitian dihitung menggunakan hasil uji statistic Chi Square dengan nilai $\alpha$ 5\% didapatkan hasil Umur ( $p$ value 0,017 dan OR 3.4), Sikap ( $p$ value 0,003 dan OR 4,3), Sumber Informasi ( $p$ value 0, 003 dan OR 3.9). Maka Ho ditolak dan Ha diterima dimana ada hubungan Umur, Sikap, sumber informasi dengan Pengetahuan Remaja dalam pencegahan HIV AIDS . Perlu ditingkatkan lagi promosi kesehatan dengan melibatkan lintas sector kepada masyarakat khususnya remaja sekolah dengan cara memberikan penyuluhan tentang HIV AIDS meliputi pencegahan penyakit menular seksual agar dapat mengurangi penularan HIV AIDS
\end{abstract}

\section{ABSTRACT :}

HIV is a group of Retroviruses that attack the human immune system, while the collection of certain clinical conditions that are the end result of HIV infection is called AIDS (Acquired Immune Deficiency Syndrome). According to approximately $50 \%$ of people with AIDS in Indonesia are adolescent age groups. During adolescence often arises a sense of wanting to try this is important for adolescent reproductive health. Behavior of wanting to try new things if encouraged by sexual stimulation can bring adolescents into premarital sex with one of the consequences of transmission of venereal diseases including HIV / AIDS). The purpose of this study was to determine the factors that influence adolescent knowledge in preventing HIV and AIDS in SMA N 7 Pekanbaru City. This research is an analytic research with Cross Sectional approach where the independent variables are Age, Attitude, Source of Information while the dependent variable is Youth Knowledge. The sampling technique was stratified with 83 respondents. The results of the study were calculated using the Chi Square statistical test results with a value of $\alpha 5 \%$ obtained results Age (p value 0.017 and OR 3.4), Attitude ( $p$ value 0.003 and OR 4.3), Information Sources ( $p$ values 0,003 and OR 3.9) . Then Ho is rejected and Ha is accepted where there is a relationship between Age, Attitude, source of information with Youth Knowledge in HIV AIDS prevention. It is necessary to increase health promotion by involving cross-sectors to the community, especially school adolescents by providing counseling about HIV AIDS, including prevention of sexually transmitted diseases in order to reduce the transmission of HIV AIDS 


\section{PENDAHULUAN}

Data BKKBN [1] menunjukkan kurang lebih $50 \%$ dari pengidap AIDS di Indonesia adalah kelompok umur remaja. Pada masa remaja sering kali timbul rasa ingin mencoba-coba ini merupakan hal penting bagi kesehatan reproduksi remaja. Perilaku ingin mencoba hal yang baru jika didorong oleh rangsangan seksual dapat membawa remaja masuk pada hubungan seks pranikah dengan salah satu akibatnya penularan penyakit kelamin termasuk HIV/AIDS [2]

Untuk mengatasi HIV/AIDS dikalangan remaja dan dewasa muda, sangat penting kita mengulas tentang apa yang mereka ketahui tentang HIV/AIDS. Remaja ingin tahu lebih banyak tentang pencegahan HIV dan program pencegahan dikembangkan secara khusus untuk remaja dan dewasa muda yang HIV positif . [3]

Menurut data Dinas Kesehatan Kota Pekanbaru (2017), jumlah kasus HIV/AIDS di Kota Pekanbaru tertinggi pertama di RSUD Arifin Achmad dan tertinggi kedua di Wilayah Senapelan dengan 56 kasus HIV dan 4 kasus AIDS. Peneliti lebih ingin melakukan penelitian di Wilayah Senapelan dikarenakan kasus HIV/AIDS yang ada di wilayah tersebut masih berada di area lingkungan masyarakat yang sesuai dengan judul penelitian yang akan dilakukan oleh peneliti.

Berdasarkan latar belakang diatas, pengetahuan tentang HIV/AIDS penting diketahui remaja karena makin meningkatnya jumlah penderita HIV/AIDS didunia tiap tahunnya. Pengetahuan sangat berpengaruh terhadap terbentuknya sikap seseorang karena ternyata sikap yang didasari oleh pengetahuan lebih baik daripada sikap yang tidak didasari oleh pengetahuan. Hal ini yang menyebabkan peneliti untuk meneliti mengenai "Faktor Yang Mempengaruhi Pengetahuan

\section{Remaja dalam Pencegahan HIV/AIDS di SMAN 7 Pekanbaru Tahun 2018?"}

\section{TINJAUAN PUSTAKA}

Penelitian yang terkait dengan penelitian ini adalah penelitian Remaja memiliki sikap yang positif untuk hindari seksual dengan banyak pasangan (91,50 $\%)$ dan gunakan jarum steril yang sekali pakai $(91,50 \%)$. Pengetahuan remaja tentang AIDS yang paling tinggi adalah penyebab AIDS $(76,60 \%)$, gejala AIDS (76,60\%), cara penularan HIV (72,30).[4]

Penelitian lain yang terkait yaitu untuk mengetahui gambaran pengetahuan siswa kelas XI tentang HIV/AIDS di SMA Negeri 1 Sungguminasa Hasil penelitian yang diperoleh yaitu pengetahuan siswa tentang penyebab HIV/AIDS sebanyak 98,12\% (261) orang, Pengetahuan siswa kelas XI tentang Gejala HIV/AIDS adalah $98 \%$ (260), Pengetahuan siswa kelas XI tentang pencegahan HIV/AIDS adalah 92,5 $\%$ (246), dan Pengetahuan siswa kelas XI tentang penularan HIV/AIDS adalah $79,7 \%$ (212).[5]

\section{METODE}

Penelitian ini merupakan penelitian analitik dengan pendekatan Cross Sectional yang bertujuan untuk mengetahui Faktor Yang Mempengaruhi pengetahuan Remaja Dalam Pencegahan HIV/AIDS di SMAN 7 Pekanbaru tahun 2018.

Lokasi Penelitian yaitu SMAN 7 Pekanbaru. Waktu penelitian ini dilaksanakan di pada bulan januari-agustus 2018. Jumlah populasi pada penelitian ini adalah 83 orang dengan teknik sampel menggunakan Stratified Random Sampling. Pengumpulan data dilakukan dengan menggunakan data primer yaitu kuesioner. Analisa data dengan menggunakan uji statistic chi square. 


\section{HASIL DAN PEMBAHASAN}

\section{Hasil}

\section{Data Univariat}

Tabel 1

Distribusi Frekuensi Karaktristik Responden Di Kecamatan Senapelan Kota Pekanbaru

\begin{tabular}{clcc}
\hline No & \multicolumn{1}{c}{ Variabel } & Frekuensi & Persentase (\%) \\
\hline 1 & Umur & & \\
& $<17$ thn & 54 & 65,1 \\
& $>17$ thn & 29 & 34,9 \\
\hline & Jumlah & 83 & 100 \\
\hline 2 & Sikap & & \\
& Negatif & 43 & 51,8 \\
& Positif & 40 & 48,2 \\
\hline & Jumlah & 83 & 100 \\
\hline 3 & Sumber Informasi & & 55,4 \\
& Non Tenaga Kesehatan & 46 & 44,6 \\
& Tenaga Kesehatan & 37 & 100 \\
\hline & Jumlah & 83 & Persentase (\%) \\
\hline No & $\quad$ Variabel Dependen & Frekuensi & 50,6 \\
\hline 1 & Pengetahuan & & 49,6 \\
& Kurang & 42 & 100 \\
& Baik & 41 & \\
\hline & Jumlah & 83 & \\
\hline
\end{tabular}

Sumber: Analisa Data Primer Tahun 2018

Berdasarkan Tabel 1 menunjukkan Berdasarkan umur bahwa mayoritas responden berumur $<17$ tahun sebanyak 54 orang $(65,1 \%)$ Berdasarkan Sikap menunjukkan bahwa mayoritas responden adalah bersikap negatif sebanyak 43 orang $(51,8 \%)$. Berdasarkan sumber informasi mayoritas responden adalah mendapatkan sumber informasi dari non nakes sebanyak 46 orang $(55,4 \%)$. Sedangkan variabel pengetahuan mayoritas responden adalah berpengetahuan kurang yaitu sebanyak 42 orang $(50,6 \%)$.

\section{Data Bivariat}

Tabel 2.

Distribusi Frekuensi Faktor-Faktor Yang Mempengaruhi Pengetahuan Dalam Pencegahan HIV AIDS

\begin{tabular}{|c|c|c|c|c|c|c|c|}
\hline \multirow[t]{3}{*}{ Umur } & \multicolumn{3}{|c|}{$\begin{array}{l}\text { Pengetahuan } \\
\text { Dalam pencegahan } \mathbf{F}\end{array}$} & & \multirow[t]{2}{*}{ Total } & \multirow{3}{*}{$\begin{array}{l}P \\
\text { Value }\end{array}$} & \multirow{3}{*}{$\begin{array}{l}\text { OR } \\
(95 \% \mathrm{CI})\end{array}$} \\
\hline & \multicolumn{2}{|c|}{ Kurang } & \multicolumn{2}{|c|}{ Baik } & & & \\
\hline & $\mathbf{N}$ & $\%$ & $\mathbf{N}$ & $\%$ & n (\%) & & \\
\hline$<17$ thn & 33 & 61,1 & 21 & 38.9 & $54(100)$ & 0.017 & 3,492 \\
\hline$>17$ thn & 9 & 31,0 & 20 & 69,0 & $29(100)$ & & (CI 95\% \\
\hline Total & 42 & 50 & 41 & 49 & $83(100)$ & & $\begin{array}{l}: 1,339- \\
9,104)\end{array}$ \\
\hline Sikap & $\begin{array}{l}\text { Pen } \\
\text { Dal }\end{array}$ & $\begin{array}{l}\text { Iuan } \\
\text { enceg }\end{array}$ & & & Total & & OR \\
\hline
\end{tabular}




\begin{tabular}{|c|c|c|c|c|c|c|c|}
\hline & \multicolumn{2}{|c|}{ Negatif } & \multicolumn{2}{|c|}{ Positif } & \multirow[b]{2}{*}{ n (\%) } & \multirow{2}{*}{$\begin{array}{c}P \\
\text { Value }\end{array}$} & \multirow[t]{2}{*}{$(95 \%$ CI $)$} \\
\hline & $\mathbf{N}$ & $\%$ & $\mathbf{N}$ & $\%$ & & & \\
\hline Negatif & 29 & 67,4 & 14 & 32,6 & $43(100)$ & 0.003 & 4.302 \\
\hline Positif & 13 & 32,5 & 27 & 67,5 & $40(100)$ & & (CI 95\% : \\
\hline Total & 42 & 50,6 & 41 & 49,4 & $83(100)$ & & $\begin{array}{l}1.716- \\
10.785) \\
\end{array}$ \\
\hline \multirow{3}{*}{$\begin{array}{l}\text { Sumber } \\
\text { Informasi }\end{array}$} & \multicolumn{4}{|c|}{$\begin{array}{l}\text { Pengetahuan } \\
\text { Dalam pencegahan HIVAIDS }\end{array}$} & Total & & OR \\
\hline & \multicolumn{2}{|c|}{ Negatif } & \multicolumn{2}{|c|}{ Positif } & & $\boldsymbol{P}$ & $(95 \%$ CI $)$ \\
\hline & $\mathbf{N}$ & $\%$ & $\mathbf{N}$ & $\%$ & n $(\%)$ & vaiue & \\
\hline $\begin{array}{l}\text { Non } \\
\text { Nakes }\end{array}$ & 30 & 65,2 & 16 & 34,8 & $46(100)$ & 0.003 & 3.906 \\
\hline Nakes & 12 & 32,4 & 25 & 67,6 & $37(100)$ & & (CI 95\% : \\
\hline Total & 42 & 50,6 & 41 & 49,4 & $83(100)$ & & $1.561-9.778)$ \\
\hline
\end{tabular}

Berdasarkan Tabel 2 menunjukkan bahwa responden dengan Umur < 17 tahun berpeluang 3.4 kali memiliki pengetahuan kurang dalam pencegahan HIV AIDS dibandingkan dengan responden dengan umur $>17$ tahun (CI 95\% =1,566-8,701). Dari hasil uji statistic Chi Square dengan nilai $\alpha$ $5 \%$ di dapat $p$ value 0,017. Artinya ada hubungan yang signifikan bermakna antara Umur Remaja dengan Pengetahuan remaja ( $p$ value $<0,05)$.

Responden yang mempunyai sikap negatif berpeluang 4,3 kali memiliki pengetahuan kurang dalam pencegahan HIV AIDS dibandingkan dengan responden yang bersikap positif.( CI 95\%: 1.716-10.785). Dari hasil uji statistic Chi Square dengan nilai $\alpha 5 \%$ di dapat $p$ value 0,003. Artinya ada hubungan yang signifikan bermakna antara pengetahuan ibu sikap remaja dengan pengetahuan remaja ( $p$ value $<0,05)$.

Responden yang mendapatkan sumber informasi dari non nakes berpeluang 3,9 kali memiliki pengetahuan kurang dalam pencegahan HIV AIDS dibandingkan responden yang mendapatkan sumber informasi dari nakes. ( CI 95\%: 1.5619.778). Dari hasil uji statistic Chi Square dengan nilai $\alpha 5 \%$ di dapat $p$ value 0,003 .
Artinya ada hubungan yang signifikan bermakna antara sikap dengan pengetahuan remaja $(p$ value $<0,05)$

\section{Hubungan Umur dengan Pengetahuan Remaja Dalm Pencegahan HIV AIDS}

Hasil bivariat menunjukkan bahwa responden dengan Umur $<17$ tahun berpeluang 3.4 kali memiliki pengetahuan kurang dalam pencegahan HIV AIDS dibandingkan dengan responden dengan umur $>17$ tahun (CI 95\% =1,566-8,701). Dari hasil uji statistic Chi Square dengan nilai $\alpha$ $5 \%$ di dapat $p$ value 0,017. Artinya ada hubungan yang signifikan bermakna antara Umur Remaja dengan Pengetahuan remaja ( $p$ value $<0,05)$.

Pengetahuan responden dipengaruhi juga oleh umur responden. Bertambahnya umur seseorang dapat mengalami perubahan baik secara fisik maupun psikologis (mental). Secara garis besar, pertumbuhan fisik terdiri dari empat kategori perubahan yaitu perubahan ukuran, perubahan proporsi, hilangnya ciriciri lama dan timbulnya ciri-ciri baru.Pada aspek fisik dan psikologis (mental), taraf berfikir seseorang menjadi semakin matang dan dewasa. (Mubarak, 2011). Ini dilihat pada hasil penelitian bahwa 
responden yang berusia $>17$ tahun lebih memiliki pengetahuan yang baik dibandingkan responden umur $<17$ tahun. Hasil penelitian [7] didapatkan data kumulatif ODHA sampai dengan bulan Juli 2009 untuk laki-laki usia kurang 15 tahun 3 kasus, 15-24 = 37 kasus, 25-49 tahun = 114, kasus, umur lebih 50 tahun 2 kasus jumlah 156 kasus. Sementara Hasil penelitian [8] menunjukkan bahwa faktor yang berhubungan dengan tindakan pencegahan penularan HIV adalah umur $(p=0,040 ; \alpha=0,05)$. Pada analisis regresi logistik ganda diketahui bahwa umur merupakan faktor yang paling mempengaruhi tindakan pencegahan penularan HIV $(p=0,031 ; \alpha=0,05 ; 95 \%$ CI: 1.169-26.423). Umur muda berisiko menularkan HIV karena cenderung melakukan seks tidak aman.

\section{Hubungan Sikap dengan Pengetahuan Remaja Dalm Pencegahan HIV AIDS}

Responden yang mempunyai sikap negatif berpeluang 4,3 kali memiliki pengetahuan kurang dalam pencegahan HIV AIDS dibandingkan dengan responden yang bersikap positif .( CI 95\%: 1.716-10.785). Dari hasil uji statistic Chi Square dengan nilai $\alpha 5 \%$ di dapat $p$ value 0,003. Artinya ada hubungan yang signifikan bermakna antara sikap remaja dengan pengetahuan remaja ( $p$ value < 0,05).

Sikap merupakan reaksi atau respon yang masih tertutup dari seseorang terhadap suatu stimulasi atau objek. Seseorang akan memberikan sikap yang positif jika mempunyai landasan pengetahuan yang kuat terlebih dahulu [9]. Sikap seseorang dipengaruhi oleh kepercayaan, emosional dan kecenderungan berfikir, keyakinan dan emosi memang berperan penting. Berdasarkan hasil penelitian mayoritas responden bersikap negative berpeluang memiliki pengatahuan yang kurang dikarenakan pengetahuan merupakan hasil dari tahu, yang terjadi setelah orang melakukan pengindraan terhadap objek tertentu. Sebagian besar pengetahuan diperoleh melalui mata dan telinga. Pengetahuan merupakan pedoman dalam membentuk tindakan seseorang (over behavior) berdasarkan pengalaman yang didapatkan oleh setiap manusia (Mubarak, 2011)

Ini juga sama dengan penelitian yang berjudul "Pengetahuan dan Sikap Siswa SMA Tentang HIV/AIDS di SMU Negeri 1 Wedi Klaten" bahwa menunjukkan adanya hubungan antara pengetahuan dan sikap. Sikap responden yang mendukung pencegahan HIV/AIDS sebagian besar $(85,7 \%)$ adalah positif. [11]. Hasil yang sama juga didapat dari penelitian yang berjudul "Hubungan Pengetahuan dan Sikap Tentang HIV/AIDS Terhadap Tindakan Pencegahan HIV/AIDS pada Pekerja Perantauan di Desa Timbul Sloko Kecamatan Sayung Demak" [12]

\section{Hubungan Sumber Informasi dengan Pengetahuan Remaja Dalm Pencegahan HIV AIDS}

Responden yang mendapatkan sumber informasi dari non nakes berpeluang 3,9 kali memiliki pengetahuan kurang dalam pencegahan HIV AIDS dibandingkan responden yang mendapatkan sumber informasi dari nakes. ( CI 95\%: 1.5619.778). Dari hasil uji statistic Chi Square dengan nilai $\alpha 5 \%$ di dapat $p$ value 0,003 . Artinya ada hubungan yang signifikan bermakna antara sumber informasi dengan pengetahuan remaja ( $p$ value < 0,05). Menurut [9] yang menyatakan bahwa informasi merupakan sumber pengetahuan. Pengetahuan seseorang akan bertambah jika ia banyak menerima informasi. Informasi merupakan pesan atau kumpulan pesan (ekspresi atau ucapan) yang terdiri dari order sekuens dari symbol atau makna yang ditafsirkan dari pesan atau kumpulan dari symbol atau makna yang ditafsirkan 
dari pesan atau kumpulan pesan yang dapat direkam atau ditransmisikan. Informasi yang di dapatkan remaja sebagain besar di dapatkan dari non tenaga kesehatan. Informasi yang di dapatkan dari non tenaga kesehatan bisa menjadi kurangnya pengetahuan remaja tentang Pencegahan HIV AIDS di karenakan informasi yang di dapatkan remaja tidak didukung dengan data yang jelas dan update.

\section{KESIMPULAN}

Terdapat hubungan yang signifikan antara Umur Remaja dengan Pengetahuan remaja dengan $p$ value sebesar 0,017 ( $p$ value < 0,05). Terdapat hubungan yang signifikan antara sikap remaja dengan pengetahuan remaja dengan $p$ value sebesar 0,003 ( $p$ value $<0,05)$. Terdapat hubungan yang signifikan antara sumber informasi dengan pengetahuan remaja dengan $p$ value sebesar 0,003 ( $p$ value < $0,05)$.

\section{DAFTAR PUSTAKA}

[1] BKKBN, Penyiapan Kehidupan Berkeluarga bagi Remaja. Jakarta, 2010.

[2] I. Kumalasari, I, Andhyantoro, Kesehatan Reproduksi untuk Mahasiswa Kebidanan dan Keperawatan. Jakarta: Salemba Medika, 2012.

[3] Noviana., Kesehatan Reproduksi Dan HIV/AIDS. Jakarta: CV. Trans Info Media, 2013.

[4] D. I. Yani, N. Juniarti, and M. Lukman, "Gambaran Pengetahuan Dan Sikap Tentang Hiv/ Aids Pada Remaja Di Pangandaran," $J$.
Pengabdi. Kpd. Masy., vol. 1, no. 1, pp. 1-5, 2017.

K. P. SAMIRA, "GAMBARAN PENGETAHUAN SISWA KELAS XI TENTANG HIV/AIDS DI SMA NEGERI 1 SUNGGUMINASA TAHUN 2013," Karya Tulis Ilm. DIII Kebidanan Fak. Ilmu Kesehat. UIN Alauddin Makassar, 2014.

[6] W. I. Mubarak, Promosi Kesehatan untuk Kebidanan. Jakarta: Salemba Media, 2011.

[7] T. Susilowati, "Faktor -Faktor Resiko Yang Berpengaruh Terhadap Kejadian HIV Dan AIDS Di Semarang Dan Sekitarnya.," $e$ journal Akbid Purwerejo, vol. 2 (1), pp. 1-8, 2011.

[8] K. K. Yowel Kambu, Agung Waluyo, "Umur Orang Dengan HIV AIDS (ODHA) Berhubungan Dengan Tindakan Pencegahan Penularan HIV," J. Keperawatan Indones., vol. 19, no. 3, pp. 200207, 2016.

[9] S. Notoatmodjo, Promosi Kesehatan Teori dan Aplikasi. Jakarta: Rineka Cipta, 2012.

[10] W. I. Mubarak, Promosi Kesehatan untuk Kebidanan. Jakarta: EGC, 2011.

[11] Handayani. S, "Pengetahuan dan Sikap Siswa SMA Tentang HIV/AIDS di SMU Negeri 1 Wedi Klaten," MOTORIK, vol. 6 (12), pp. 1-7, 2011.

[12] H. D. Astutik, "Hubungan Pengetahuan dan Sikap tentang AIDS terhadap Tindakan Pencegahan HIV/AIDS pada Pekerja Perantauan di Desa Timbul Sloko Kecamatan Sayung Demak.," Univ. Islam Sultan Agung, 2014. 